\title{
Unruly Experts: Methods and Forms of Collaboration in the Anthropology of Public Policy
}

\section{Tara Schwegler and Michael G. Powell}

We never seek out frustration, but it almost always finds us. Seasoned field researchers, anthropologists pride themselves on their ability to handle life's curve balls, from visa problems to cultural misunderstandings to difficulties in gaining access to informants. These curve balls go hand in hand with the home runs: all are moments in fieldwork, wherever, however, and among whomever conducted, and each moment has a story. Nevertheless, once the anthropologist exits the field and returns to the desk (a classic Malinowskian distinction under increasing strain over the past two decades), the stories split into two categories-the planned episodes of data collection that conform to pre-conceived standards for scholarly evidence and the unanticipated events and anomalous occurrences relegated to the genre of colourful field anecdotes. Whereas the former constitutes the storehouse of ethnographic data inserted into scholarly articles and publications, the latter is regarded as appropriate fodder for hallway chatter (Rabinow 1996). But frustration plays a markedly different role in the two genres: the informal stories capitalise on frustration and contingency to garner laughs and/or sympathy, while the formal stories sweep frustration under the rug and replace it with a narrative of steady progress in data collection.

Our frustrations, despite their invisibility in the final account, result in enormously productive experiences and data collection opportunities. When we encounter a snag in field research, we devise logical alternatives to the original strategy. Identifying the nature of perceived obstacles and re-assessing the methods to overcome obstacles require a firm grasp of research aims, a creative engagement with existing research methods and, above all, an intimate knowledge of the fieldwork context. It is the ethnographic equivalent of making recipe substitutions on the fly. Just as making substitutions requires an overall sense and awareness of the qualities and potential interactions among ingredients, research tribulations force us to confront our deep-seated assumptions about the field and our methods or consider alternative conceptualisations and strategies. Sustained, systematic and candid engagement with trials and tribulations of multiple forms can reap essential methodological insights.

Nowhere are these observations more relevant than in the emergent anthropology of policy, where anthropologists grapple with and struggle to find their way into rigidly institutionalised contexts. As an emergent field that blurs the boundaries of anthropological epistemology, the anthropology of policy engages with and within powerful institutions at the local, national and international level in order to decipher and delineate the ways in which they draw together and make possible new configurations of power and knowledge. Accordingly, the field transcends geographiccentred definitions and looks to connections in and between networks of actors as particularly fertile staging grounds for investigations. In a similar vein, it transgresses the comfortable distinction between the subject and object of ethnographic study because it involves institutional actors who are either experts themselves or keenly attuned to the institutional structures that validate anthropological expertise, 
possessing the wherewithal to demand 'objectivity' in the Latourian sense (Mosse 2006). Anthropology of policy destabilises these political distinctions, making it a unique place to examine anthropological theory and methods about epistemology and power.

We independently came to this realization through our shared conviction that the anthropology of policy, generally conducted in settings and under circumstances not amenable or conducive to the traditional ethnographic gaze, forces the pragmatic considerations of fieldwork methods to reconsider the broader framework of fieldwork methodology and the epistemology of anthropological knowledge. The question we pose here is how do the unruly or uncanny circumstances of fieldwork in the anthropology of policy change the way in which we think about methodology and the epistemology of anthropological knowledge? Such discussions often occur imperceptibly, out of earshot of the normal details of fieldwork because they are seen as irrelevant to highfalutin theoretical considerations. We contend that the nature of fieldwork in the anthropology of policy renders the accidental, the contingent and, most importantly, the frustrating as a rich store of insights on methods and ultimately forms a part of data itself.

In considering new approaches and more established perspectives, this volume brings together junior and senior scholars who have either conducted field research in the anthropology of policy or whose work suggests future directions for the anthropology of policy. It does so not for the purpose of laying out a fixed methodological programme for the subfield, but rather, for assembling ethnographic experiences to reflect on research strategies and design. In particular, we want to investigate the forms and benefits of specific and generalisable fieldwork relationships that emerge in the process of ethnographic research. We have invited authors to reflect on the success and failures in their field research not with an eye to producing an exhaustive laundry list of what works and what does not, but to draw attention to how the very pathways and processes of obtaining access to specific individuals or research contexts are themselves data.

Recent discussions of how anthropology will maintain its disciplinary integrity under the twin circumstances of globalisation, where traditional fieldwork has become increasingly untenable, and interdisciplinary fields poach ethnographic territory, have forced us to reconsider where we regard ethnographic data to reside and why we are uniquely qualified to discover them. In this volume, we raise the prospect that ethnographic data do not lie solely in the verbatim words of an informant, nor in the triangulation of multiple accounts and perspectives, but also in the complex tangle that we negotiate to get to the informant in the first place. Informants' understandings of the world form a crucial piece of the puzzle, but they cannot adequately contextualise themselves without attention to the institutional frameworks and interests in which they are situated. If anthropological knowledge is indeed always relational (Hastrup 2004), we must devote more systematic attention to these contexts. Failure, frustration and dead ends are a crucial component of these problems.

\section{Systematicity and Serendipity: Rethinking Fieldwork through the Anthropology of Policy}

While anthropologists have long studied powerful institutions and elites, most contemporary anthropological research in this vein has confined itself to examining the effects of regimes of calculation and rationalisation on the daily lives of citizens (Miller and O'Leary 1994) or how policies, however well intended, have gone horribly wrong, in practice (Scott 1998; Li 2007). The emergent field of the anthropology of public policy aims to combine an interest in the effects of policy with an intimate understanding of the mechanisms 
behind its development, proliferation and implementation. The anthropology of policy engages with and within powerful institutions at the local, national and international level in order to decipher and delineate the ways in which they draw together and make possible new configurations and forms of power and knowledge (Shore and Wright 1997; Wedel et al. 2005). In a world in which so much is in flux, policy has emerged as a potentially useful organising principle for ethnographic projects that explore 'assemblages' of ideas in 'specific substantive or value orders' (Ong and Collier 2005: 13).

The anthropology of policy has attracted widespread attention within the discipline in part because it responds to the growing discomfort with traditional models of fieldwork in an era of globalisation. While debate continues concerning the novelty of globalisation, the discourse of globalisation in the last fifteen years has left an indelible imprint on the anthropological landscape. George Marcus (1998), Akhil Gupta and Jim Ferguson (1997) and others have warned of the analytical limitations of a place-based, single site model of fieldwork that discovers essential truths of a culture and demands that an ethnographer need only insert herself into a specific locale and plug away until she finds it. Anthropologists have slowly warmed to the idea of interstitial truths, relational data, and the politics of representation, but the assumption of a single, fixed field site remains deeply embedded in our way of thinking. Quite simply, what we say and what we do are not altogether the same thing. Policy forces the issue, however, for several reasons. First, policy is never a discrete geographical phenomenon. Though policy may generally issue forth from a government or an institution empowered to govern a specific group of people (a corporation, an institution, etc.), a moment's reflection quickly reveals that the origin of policy is far more complicated than it initially seems. Where is policy spatially located? Does it begin when formally implemented by an assembled group? Does it begin when someone identifies a problem as requiring a solution? Does it happen when a group with divergent interests effectively enrolls a network through the realisation of a shared agenda, (to employ actor-network terminology)? Did the policy come from local or international sources or does it matter at all? All of these are plausible questions and answers, and their mutual inclusivity suggests that policy takes shape in a variety of locations. Second, policy is not a material object, so it is not entirely amenable to the 'follow-the-object' strategies. Instead of tracking the visible movement of an object through contexts, anthropology of policy more clumsily adumbrates multiple networks and determines possible interconnections. In attempting to grasp difficult objects and slippery cultural concepts, the kinds of challenges that the anthropology of policy faces are not dissimilar to the concerns that grip much of the discipline.

While the anthropology of policy speaks to a number of widespread concerns within the discipline, it nevertheless has its share of unique considerations. Projects inevitably become entangled in political complexity, ambiguity or even intrigue. Broadly construed, policy need not concern politics explicitly (we may speak of corporate policy, university policy, etc.), though anthropologists have positioned most existing studies within or adjacent to the political field. Conditions of access to individuals and information might be different under such circumstances, and the anthropologist can hardly inoculate herself against politics. Often the anthropologist unwittingly gets caught up in public political struggles (Mosse 2006) or may participate in the elaboration of political networks (see Schwegler and Powell, this volume). The fact that we deal with politics does not entirely foreclose the possibility of single-sited participant observation in powerful institutions (see Harper 1998), but practical considerations of confidentiality generally rule 
out participant observation as the cornerstone method. Different objects of study require different methods of inquiry and research.

Additionally, policy places anthropologists in contact with members of a different sort of subject community, composed mainly of professionals and experts who do not necessarily live close to one another and may or may not even socialise with one another. Rather, these flexible and sometimes itinerant communities of professionals and experts associate and identify for very specific purposes. By professionals, we mean individuals who occupy formal positions within institutional structures, with the implication that they have reputations to consider and likely exert greater control over information and identification. By experts, we refer to individuals who have qualifications or credentials that validate their mastery of a particular form of knowledge. For the purposes of this volume, the two identities co-mingle-professionals generally possess a form of expertise that authorises their appraisal of anthropological knowledge-that is, policy makers occupy an institutional position and possess the relevant expertise to offer trenchant commentary (and possibly, criticism) on the anthropologist's findings. As Boyer (this volume) points out, anthropologists have always been subject to the appraisals of their informants, but the institutional weight and high profile of many of our interlocutors in the anthropology of policy adds a new dimension to the relationship between the anthropologist and her interlocutors.

The anthropology of policy problematises traditional fieldwork contexts and relationships in new ways. In keeping with the theme of the volume, we are less interested in lamenting the obstacles to traditional fieldwork than in exploring the possibilities these new contexts and relationships offer for anthropological understanding. Although certain relationships may close off, new forms, methods and ways of knowing develop. We could shed much potential anxiety over what our disci- pline has lost by focusing on what constitutes 'the field' and thinking about what constitutes fieldwork-the mores, the strategies, techniques, relationships and inter-subjective experiences-that increasingly characterise anthropology in the twenty-first century. When we fix our attention on geographically defined field sites or their absence, we enfold ourselves in a cosmology of control that rehearses the many oppositions that have previously structured fieldwork experience: inside versus outside, research versus writing, field versus desk. All of these distinctions speak to locations and in so doing assert a false sense of control over the events and situations in which anthropologists find themselves. Our best instincts warn us to the contrary, that research and interpretation are dialectical and dynamic processes generally carried on simultaneously, but the oppositions nevertheless persist. We may easily add to the list, plan versus accident. It is hard to admit that stumbling blocks may have triggered important findings or discoveries and that serendipity lies at the core of some of our greatest insights. Admissions of this sort offend our well-cultivated positivistic assumptions in several ways. First, they suggest that if the exogenous event had not occurred, the finding would not have been made, implying that perhaps the fieldworker is not in perfect control of the circumstances of his research (which we all know they are not, but we take collective comfort in ignoring this). Second, it presses upon an already consistent sore point among anthropologists: what can be systematic about research that is abetted by serendipity, whether it is initially recognised as such or not?

Our analytical discomfort with those experiences that do not seem to fit the mould of anthropological fieldwork starts to melt away when we think about anthropological fieldwork as an orientation, a sensibility about the world that foregrounds experience, everyday practices and meaning. The analytical posture we assume is not like an investigative journalist 
who seeks to discover 'what really happened' by contacting all the relevant parties. Although we can learn a lot from investigative journalists by way of tactics and techniques, our purposes and pioneers are somewhat distinct. Long ago, anthropologists and other relativistic social scientists abandoned lofty presumptions of absolute truth. We are, instead, interested in the context that makes certain possibilities thinkable and others not, the circumstances that lead individuals to take one decision over another and the manifold contingencies and negotiations of everyday life. An anthropology of policy, for example, might investigate what made an investigative report about corruption seem true, feel relevant and have an impact in a national context already entrenched in anti-corruption policies. Across a wide range of disciplines and professions, contemporary subjects embrace the notion that an agent will never be able to access all relevant information at any one time (Beck 1996). Certainties are replaced with elliptical possibilities, and when conducting field research under such circumstances, anthropologists must devise flexible strategies to be conceptually grounded, yet dynamic, field workers. Thus, we do not deliver a eulogy for systematicity in field research. Rather, we asked our contributors to reflect on how to formalise these diverse strategies into something more than muddling through. How do we systematically integrate new sources and modes of data into a coherent rationale that is responsive and adaptable to the new circumstances that emerge in the course of fieldwork?

It is one thing to propose that anthropology is a sensibility rather than an exclusively methods-driven discipline, quite another to elaborate what, precisely, this sensibility is and what types of data and techniques it entails. This is where the dynamic interaction between actual field experiences and theoretical reflections comes into play. We hope to pose answers to some of these questions from a variety of perspectives so that readers can pick and choose what might be useful in their own research contexts. In doing so, we underscore that this volume is not an attempt to formalise the methods of an anthropology of policy. We do not want the anthropology of policy to become a toolkit of one-size-fits-all methods for field research on policy, but rather aspires to use the diverse experiences of its practitioners as a guide for ongoing discussion and search for this elusive sensibility. This volume intends to help flesh out some central issues, to reflect on our experiences as theoreticians and fieldworkers and to reveal what these experiences might tell us about the future directions of the anthropology of policy.

\section{Experts, Expertise and Collaboration}

While anthropologists have made an art of integrating themselves into a local community, increasingly community has been defined less by physical contiguity or geography and more by epistemological affinity, shared meanings and common interpretative tendencies. There are policy communities just as there are local communities, and the task of the anthropologist of policy is to obtain access to members of this community. And as communities change, so must the ways in which anthropologists incorporate and integrate themselves into them.

Several factors complicate this task. First, there is the sheer reality of limited time, which strikes everyone, not only those in high places. Members of a policy community often occupy positions in local, national or international institutions. While confidentiality pledges and a general desire to avoid prying eyes may account for some difficulty in obtaining access to these figures, the importance of time must not be underestimated. Practically speaking, a willing but unable official is of little more use than an unilling but able one.

Second, there is the matter of overlapping, yet distinct, epistemologies of knowledge between the anthropologist and her interlocutor. 
Public officials frequently have some knowledge of anthropology and the nature of ethnographic research. Though they may not be aware of the nuances of anthropological theory, they are capable and well equipped to dispute our findings or methods and critique our epistemological foundations altogether. The turn towards the politics of representation in the 1980s heightened anthropologists' sensitivity to the need to view informants as active participants in the production and authorization of anthropological knowledge. But the question of how to proceed when one's informants are experts sanctioned by the very institutions that validate and authorise anthropological conventions raises novel, if not entirely new, considerations for the anthropology of policy. The critique of representation raised in the 1980s, as well as a heightened concern over politics in the 1970s (Hymes 1972), raised concerns over furthering imperialism and the violence anthropologists could do to subaltern subjects. An anthropology of policy raises slightly different epistemological concerns exactly because we are trying to study and honestly document the lives of powerful subjects, many of whose legitimate knowledge forms we often find problematic.

The complexities of working with expert informants are multi-layered. In the vein of frustration, perhaps not a single anthropologist who studied policy has been spared the slew of calls to secretaries, appointments cancelled at the last minute, and long hours spent in waiting rooms that accompany nearly every effort to meet with a public official. A Mexican official once told Schwegler that you can judge how important an official is by how hard it is to meet with him-and if he is too accessible, then perhaps you have wasted your time interviewing him! Powell, too, spent months tracking down various officials and investigative journalists, frustrated by frequent cancelled meetings. Access is the most frequently articulated concern of anthropologists in training.
From the outset, we have sensed that the pragmatics of access to powerful actors/ institutions is fundamentally linked to theoretical discussions on the nature of ethnographic knowledge and the strategies by which ethnographic objects are formulated. For instance, questions of how to obtain access to powerful figures are tied to questions of how the political field is organised and how the anthropologist can position himself within it. We posit that frustrated attempts generate data because they reveal the implicit topography of power and influence in a specific political field. Schwegler and Powell both came to much more expansive understandings of institutional power relations when their respective efforts to contact officials depended on referring parties (this issue). Frustrations also offer a crucial glimpse of how the anthropologist is viewed by her interlocutors. By comparing the relative ease or difficulty with which one gains access, the anthropologist can ascertain the type of interest an anthropologist attracts in a particular setting and why. Pinpointing the various ways in which our interlocutors understand our presence and our research helps us to more effectively manoeuvre in these spaces.

The second layer of consideration is the type of possible fieldwork relationships in such settings. If, as we earlier proposed, the anthropology of policy necessitates thinking beyond the traditional 'depth' model of field research in which the anthropologist is either 'in' or 'out', these less immediate relationships between anthropologist and interlocutor, while certainly cordial, may instead consist of neither rapport nor complicity. Compounding the complexity, our interlocutors often consider and scrutinise our findings, and may actively contest and critique them by impugning the anthropologist's authority (Mosse 2006). In other cases, they may compartmentalise our findings or observations as a non-threatening, impossible to categorise or simply useless perspective. What is certain is that the response will 
not be uniform-different interlocutors will react in different ways. Some who exhibit a para-ethnographic tendency - that is, 'the de facto and self-conscious critical faculty that operates in any expert domain as a way of dealing with contradiction, exception, facts that are fugitive' (Holmes and Marcus 2005: 237)—might greet our publications enthusiastically, while others might attempt to discredit the anthropologist. The potential responses to ethnographic inquiry span the gamut and the anthropologist of policy must enter with a healthy respect that neither under- nor over-estimates the cordiality of the reception she will encounter. Hopefully, this volume helps the anthropologist of policy anticipate potential responses and strategies for working within subjects by reviewing a broad spectrum of field experiences.

It stands to reason that the wide array of expert responses to the anthropologist's presence and findings expands the possible forms of fieldwork relationships and, indeed, the possibilities for collaboration. We have chosen the analytic frame of 'collaboration' to underscore the dynamic forms of knowledge production that may open between the anthropologist and the policy maker. The term 'collaboration' intends to invite reflection on the types of field relationships and research strategies that have been effective in specific settings and why. That is, rather than presuming that institutionalised relationships inhibit the pursuit of anthropological knowledge, we seek to explore the ways in which these relationships offer new methodological possibilities.

Collaborative ethnography denotes a range of fieldwork relationships that align the purposes of the researcher and interlocutor. It may assume a variety of forms, from data collection to writing field notes, but it almost always relies on an explicit metaphor of conversation and/or dialogue (Lassiter 2005). Para-ethnographic collaboration is an important variation of this form, in which researchers tap into the sensibilities of individuals who maintain a critical and self-reflexive stance in their professions (Holmes and Marcus 2005). Yet, it stands to reason that the diversity of responses and engagements with the anthropologist's presence and findings opens the door to multiple permutations and forms of relationships. These hybridised relationships involve a relationship that often hovers somewhere between rapport and complicity, a relationship that projects in the anthropology of policy are uniquely poised to generate.

The term 'collaboration' also heightens our sensitivity to the complex nature of anthropological critique in contemporary settings. Acting as a voice for marginalised groups, anthropologists have traditionally felt compelled to represent their subjects in favourable ways. What happens when anthropologists criticise their constituency? What happens when their subjects are already quite powerful policy making institutions whose policies and their implementation deserve critical rejoinder? And in the spirit of collaboration, what happens when anthropologists contribute to the policy conversation that also serves as their field site? Once again, we return to the productive tension between theory and methods: as a form of critique, does the anthropologist and anthropological knowledge stand in direct opposition to formal institutions, or are there ways of rethinking the forms of relationships between the anthropologist and his/her interlocutors that facilitate critical dialogue or even a critical collaboration? The volume seeks to explore the varieties of possible fieldwork relationships in an era and context where straightforward rapport is not always possible or even wise.

\section{Conclusion}

Why study policy? Why try to figure it out? As ambitious or even naïve as it may sound, we study policy because we want to understand how power works today. It is a 
complex world of bureaucracy, technocracy, professionals, elites, experts and officialdom. Above all, and following Foucault, we recognise that power and knowledge are inextricably intertwined. As much as an anthropology of policy examines power, it examines knowledge and knowledge production. It examines knowledge production in an essential context, institutional settings where knowledge holds special weight because this is where it is put into action by the experts and bureaucrats who formulate, theorise and extrapolate that knowledge. As anthropologists have looked at so many mechanisms of power, it only makes sense then that policy becomes yet another target for enquiry.

As scholars of power, we know that power defies, denies and eludes study. For every grand theory of power or political economy, for every critic or anthropologist who excavates the forces of hegemony, imperialism or dominance in the most mundane of everyday practices, there is the technocrat, bureaucrat or official expert who lays claim to an institutionally legitimate and academically commensurate interpretation of the world. So what does the anthropologist bring to the table? First, anthropologists maintain a healthy skepticism of the discourses and practices that naturalise institutional power and insulate them from interrogation, a distanced perspective that enables us to shed new light on processes that our informants take as given. Second, our methodological agility enables us to piece together sides of their story that our informants cannot because of their very different relationship configurations of power and collegiality. We occupy a much different position in the institutional structure: neither interloper nor direct participants, we become privy (and enmeshed in) the multiple interpersonal contexts nested within an institutional setting. In studying policy, however, we cannot rely on knowing something that our informants do not and we cannot expect to outsmart them or merely uncover a false consciousness. As our informants, after all, we need to respect them and their worldview before we seek to criticise.

By exploring the methodology of public policy, this volume is situated at the juncture of the anthropological study of powerful institutions and elites, research design and methodology and critical theory. Through outlining the types of research strategies that have been useful and why, all of our contributors offer an implicit consideration of the following questions: what are the possibilities for a critically engaged anthropology of policy that neither justifies the status quo nor takes an a priori antagonistic stance towards powerful institutions? What are the ways in which projects in the anthropology of public policy have addressed these concerns, and what new concerns have they raised?

\section{Acknowledgments}

The authors owe an enormous debt of gratitude to the participants in the November 2006 roundtable, 'Turning Lemons into Lemonade: What the Anthropology of Public Policy Can Learn from Methodological Frustration', at the annual meetings of the American Anthropological Association in San Jose, California. Greg Feldman, Susan Greenhalgh, George Marcus, Angela Rivas, and Christopher Timura accepted the somewhat unconventional invitation to participate in a semi-structured roundtable format designed to open up new conversations in the anthropology of public policy. While not all of them were able to contribute to this volume, the insights that they brought to the table, so to speak, are reflected in this introduction. The authors also thank Janine Wedel, Greg Feldman, Marietta Baba, Don Brenneis, Cris Shore, and Susan Wright for their enthusiastic support of the roundtable and this volume. Chris McCourt and her pred- 
ecessor, Jonathan Skinner, have provided exceptional guidance and insights to help bring this volume to fruition.

\section{References}

Beck, U. (1996), 'Shut Up and Dance, Or, Is the World Economy Knowable?' in The Global Economy in Transition, (ed.) P. W. Daniels and W. F. Lever (New York: Longman), 11-23.

Gupta, A. and Ferguson, J. (1997), 'Discipline and Practice: "The Field" as Site, Method, and Location in Anthropology', in Anthropological Locations: Boundaries and Grounds of a Field Science, (ed.) A. Gupta and J. Ferguson (Berkeley: University of California Press), 1-46.

Harper, R. (1998), Inside the IMF: An Ethnography of Documents, Technology and Organisational Action (San Diego: Academic Press).

Hastrup, K. (2004), 'Getting it Right: Knowledge and Evidence in Anthropology', Anthropological Theory 4, 455-472.

Hymes, D. (1972), Reinventing Anthropology (New York: Pantheon).

Lassiter, L. (2005), 'Collaborative Ethnography and Public Anthropology', Current Anthropology 46, no. 1: 83-106.

Li, T. (2007), The Will to Improve: Governmentality, Development, and the Practice of Politics (Durham, NC: Duke University Press).

Marcus, G. (1998), 'Ethnography in/of the World System: The Emergence of Multi-Sited Ethno- graphy', in Ethnography Through Thick and Thin (Princeton: Princeton University Press), 79-104.

Marcus, G. and Holmes, D. (2005), 'Cultures of Expertise and the Management of Globalization: Toward the Re-Functioning of Ethnography', in Global Assemblages: Technology, Politics, and Ethics as Anthropological Problems, (ed.) A. Ong and S. Collier (Malden, MA: Blackwell), 235-252.

Miller, P. and O'Leary, T. (1994), 'Governing the Calculable Person', in Accounting as Social and Institutional Practice, (ed). A. Hopwood and P. Miller (New York: Cambridge University Press), 98-115.

Mosse, D. (2006), Anti-social Anthropology? Objectivity, Objection, and the Ethnography of Public Policy and Professional Communities', Journal of the Royal Anthropological Institute 12: 935-956.

Ong, A. and Collier S. (eds.) (2005), Global Assemblages: Technology, Politics, and Ethics as Anthropological Problems (Malden, MA: Blackwell).

Rabinow, P. (1996), Essays in the Anthropology of Reason (Princeton: Princeton University Press).

Scott, J. (1998), Seeing Like a State: How Certain Schemes to Improve the Human Condition Have Failed (New Haven: Yale University Press).

Shore, C. and Wright, S. (1997), 'Policy: A New Field of Anthropology', in Anthropology of Policy: Critical Perspectives on Governance and Power (ed.) C. Shore and S. Wright (London: Routledge), 3-42.

Wedel, J., Shore, C., Feldman, G. and Lathrop, S. (2005), 'Toward an Anthropology of Public Policy, The Annals of the American Academy of Political and Social Science 600: 30-51. 